\title{
Protective Ventilatory Approaches to One-Lung Ventilation: More than Reduction of Tidal Volume
}

\author{
Alf Kozian - Thomas Schilling
}

Published online: 13 March 2014

(c) Springer Science + Business Media New York 2014

\begin{abstract}
The thoracic surgical patient is at special risk for increased postoperative pulmonary complications, such as atelectasis, impaired lung function and pneumonia, as well as acute lung injury (ALI) and acute respiratory distress syndrome (ARDS) with high mortality after lung resections. One-lung ventilation (OLV) induces proinflammatory responses especially in the ventilated lung, based on mechanical stress, persistent hyperperfusion, increased gas content and ventilation to perfusion mismatching. ALI may occur, even in previously healthy lungs. Ventilation management can cause and exacerbate but also attenuate ALI after OLV. Protective ventilatory approaches can improve the outcome by minimizing lung damage. However, ventilation with lower tidal volumes during OLV does not completely abolish alveolar inflammation. The present review addresses the effects of OLV and their role in ventilator-induced lung injury. Lung protective strategies to one-lung ventilation that additionally include reduction of cyclic alveolar recruitment, PEEP ventilation, limitation of inspired oxygen and pharmacological preconditioning by volatile anesthetics are discussed.
\end{abstract}

Electronic supplementary material The online version of this article (doi:10.1007/s40140-014-0057-6) contains supplementary material, which is available to authorized users.

A. Kozian · T. Schilling ( $\square)$

Department of Anesthesiology and Intensive Care Medicine,

Otto-von-Guericke-University, Leipziger Str. 44,

39120 Magdeburg, Germany

e-mail: thomas.schilling@med.ovgu.de

A. Kozian

e-mail: alf.kozian@med.ovgu.de
Keywords Thoracic anesthesia - One-lung ventilation . Ventilator-induced lung injury $\cdot$ Atelectrauma $\cdot$ Lungprotective ventilation strategies $\cdot$ Alveolar recruitment maneuver - Anesthetics · Cytokines

\section{Introduction}

The patient scheduled for thoracic surgery is at risk of increased perioperative respiratory morbidity and mortality [1-3]. Lung resection is associated with a mortality of about $2.5 \%$, which is mainly determined by pulmonary complications [4-7], but the underlying mechanisms have not been fully understood yet.

Pulmonary injury has been recognized as a complication of lung resection since Zeldin et al. [8] reported ten cases of acute lung injury following thoracic surgery and introduced the term "post-pneumonectomy pulmonary edema" (PPE) in 1984. A former study of 806 patients with pneumonectomy revealed an incidence of $2.5 \%$ for PPE with $100 \%$ mortality in affected patients [9]. However, PPE is not limited to pneumonectomy but may also occur after lobectomy and minor procedures with lower incidence and better outcome.

In the comprehensive form, the clinical course of PPE is indistinguishable from acute respiratory distress syndrome (ARDS) as defined by the American-European Consensus Conference on ARDS [10]. However, many patients do not meet the diagnostic criteria for ARDS but fulfill those of less severe acute lung injury (ALI). Hence, the reported incidence for PPE differs with rates of 4-7\% for pneumonectomy and 1-7 \% for lobectomy with a mortality of $40-70 \%$ [11]. In fact, ALI/ARDS is the major cause of death in the respective patient group after thoracic surgery [12]. 
The following factors were identified as independent predictors of primary ALI after lung resection: The use of high intraoperative ventilation pressures, excessive volume replacement, pneumonectomy and preoperative alcohol abuse [6]. In addition, ALI characteristics include an incidence after pneumonectomy of 2-4\%, greater occurrence after right compared with left pneumonectomy, onset 1-3 days post-surgery, high mortality and resistance to standard therapies.

\section{Pathogenesis of Lung Injury: Surgical Trauma}

Surgical lung trauma is a potent trigger of postoperative alveolar damage. The mechanism of lung injury produced by surgical intervention itself is different from that induced by mechanical ventilation. The operated, nondependent lung suffers from temporary collapse, instrumentation and manipulation. The surgery-induced injury depends on the duration and invasiveness of the procedure [13-15], the lung resection type [16] and location of the thoracic surgical procedure [17]. Hypoperfusion induced by hypoxic pulmonary vasoconstriction [18], dysfunction of the surfactant system [19] and oxidative stress resulting from reexpansion [20], ischemia and reperfusion [21] may increase alveolar injury during and after thoracic surgery as observed in rabbit lungs after complete collapse and reventilation [22]. Impaired lymphatic drainage and fluid overload were also identified as corroborating the deleterious effect of mechanical ventilation.

In addition, translocation of proinflammatory mediators from the lung [23] induced by either surgery or injurious ventilation is considered a source of systemic inflammation that in turn possibly affects the contralateral lung.

\section{Alveolar Inflammation After Thoracic Surgery}

Acute proinflammatory responses are evident in all types of thoracic surgery [11]. They are well described in relation to ALI/ARDS [24]. The damage after lung resection probably represents the pulmonary manifestations of an inflammatory injury. The disturbance of endothelial integrity leads to changes in permeability, the loss of high amounts of protein into the alveolar space and characteristic histological changes. These histological and morphological changes are equivalent, if not identical to those of ARDS.

Accordingly, histological analysis of diffuse alveolar damage in a porcine model of thoracic surgery [25] established considerable alveolar and interstitial edema, neutrophil infiltration, alveolar overdistension, microhemorrhage and microatelectasis in the temporarily collapsed, surgically manipulated lung, but much more in the ventilated lung [26]. The detection of a diffusely distributed alveolar damage in both lungs indicates that mechanical ventilation may be as harmful as a period of complete lung collapse and manipulation during thoracic surgery.

\section{Ventilator-Induced Lung Injury (VILI)}

Mechanical two-lung ventilation itself produces homogeneously distributed alveolar damage [26] and generates an inflammatory response in the alveoli, even in healthy lungs [27]. The resulting ventilation-induced lung injury (VILI) [28] is characterized by dysfunction of the surfactant system [29], alveolar and interstitial edema [30], leukocyte recruitment [31], cytokine production [32] and neutrophildependent tissue destruction [33].

Different mechanisms during mechanical ventilation may lead to cellular activation and mediator release. These are in particular mechanical forces applied to the lung tissue, which may result in alveolar cell stretch and overdistension, shearing forces secondary to repeated tidal collapse and re-opening of alveolar units [34] and increased vascular shearing stresses [35-38]. As a result, experimental and clinical studies on two-lung ventilation $[39,40]$ have already revealed progressive alteration of the pulmonary immune function during anesthesia and surgery.

\section{One-Lung Ventilation (OLV)}

The ventilator-induced pulmonary trauma is further amplified by exclusion of the surgically treated lung from ventilation and the delivery of the entire tidal volume to the remaining lung (one-lung ventilation, OLV). The ventilation of only a single lung may be associated with lifethreatening gas exchange impairment [41, 42]. In fact, OLV may be associated with a decrease of arterial oxygen saturation below $90 \%$ in $\sim 10 \%$ of patients [43, 44]. Hypoxemia during thoracic surgery is not mainly caused by a reduced alveolar surface but much more by venous admixture resulting from residual perfusion of the nonventilated lung and from atelectasis and poorly aerated regions in the ventilated lung. Atelectasis formation has been demonstrated to be connected with decreased arterial oxygen tension of more than $50 \%$ and increased intrapulmonary shunt of $>11 \%$ during OLV [45]. Therefore, a traditional approach to mechanical ventilation during OLV [46, 47] included the application of relatively high tidal volumes in the range of $10-12 \mathrm{ml} / \mathrm{kg}$ with zero PEEP in the dependent ventilated lung to maintain hypoxic pulmonary vasoconstriction and thus to overcome hypoxemia during OLV. 
Relatively too high tidal volumes $\left(V_{\mathrm{T}}\right)$ and subsequently increased airway pressures are considered to be injurious during OLV [6, 48] in terms of increased mechanical stress, characterized by increased cyclic recruitment/derecruitment during OLV [49, 50••]. As a result, OLV may aggravate the alveolar damage followed by a permeabilitytype pulmonary edema with diffuse alveolar injury [51], leukocyte sequestration [31] and alveolar cytokine release [52]. OLV thus contributes to postoperative pulmonary morbidity through induction of a truly asymmetric lung injury following thoracic surgery [53]. Lung computed tomography (CT) scans indicated an enhanced lung density in comparison with preoperative images in thoracic surgical patients who developed ALI/ARDS after lung resection [53]. Importantly, consolidated lung tissue was detected almost exclusively in the non-operated, ventilated lung. As a consequence, OLV is considered to be a major pathogenic factor in the development of clinically relevant pulmonary complications after thoracic surgery [2].

However, as understanding of the underlying mechanisms of ventilation-induced lung injury increases, anesthetic care for patients undergoing OLV has been questioned as well. Protective ventilation approaches during OLV including smaller tidal volumes [54, 55] with lower inspiratory pressures (volume- and pressure-limited ventilation) seem to be also favorable in patients undergoing thoracotomy [56]. Furthermore, experimental data from an isolated rabbit lung model suggest that protective one-lung ventilation with tidal volumes and PEEP set to avoid lung collapse and overdistension is able to minimize ventilation-induced lung injury [57].

In contrast, a time-dependent increase of proinflammatory parameters was established in thoracic surgical patients undergoing OLV with high and low $V_{\mathrm{T}}$. The concentrations of inflammatory mediators in tracheal aspirates were not different between the two ventilator settings, and neither time course nor concentrations of pulmonary or systemic mediators differed between the patient groups [52].

\section{Mechanisms of Lung Injury}

Several OLV-related factors for postoperative respiratory failure have been recognized including ventilation to perfusion mismatch, increased transpulmonary pressures (i.e., pulmonary capillary pressures), cyclic collapse and recruitment of lung tissue [57] and tidal volumes as used during normal ventilation with subsequently increased airway pressures [58, 59].

Airway pressures above $30 \mathrm{cmH}_{2} \mathrm{O}$ and tidal volumes of 8-12 ml/kg during OLV [60] may promote alveolar overdistension. However, a protective ventilation approach to prevent lung injury during OLV by reducing tidal volumes and application of PEEP did not completely inhibit thromboxane $\mathrm{B}_{2}$ formation in isolated rabbit lungs [57] or enhance the alveolar proinflammatory response in rats [61]. Likewise, OLV with tidal volumes of $5 \mathrm{ml} / \mathrm{kg}$ only partially decreased expression of proinflammatory interleukin8 , tumor necrosis factor $\alpha$ and neutrophil infiltration in patients undergoing thoracic surgery and OLV [62]. As a consequence, high tidal volume ventilation may not be the only variable that affects alveolar integrity during and after OLV.

Collapsed lung tissue or atelectasis is the major source of deterioration of arterial oxygenation during OLV [41]. In addition, mechanical lung injury by cyclic collapse and re-opening of alveoli cannot solely attribute to the use of high tidal volumes. Low tidal volume ventilation may harm small peripheral airways by cyclic opening and closing, which results in changes in lung mechanics [63]. Supplementary mechanisms contributing to the deleterious effects of OLV contain changes in pulmonary blood flow characteristics and persistent atelectasis formation with increased shunt perfusion.

The increase of pulmonary capillary pressure during OLV [62] may also harm the pulmonary blood-gas barrier and cause fluid extravasations into the interstitial space and the alveoli, resulting in a pulmonary edema.

In summary, perioperative ALI is of multifactor origin. Mechanical stress by hyperinflation, hyperperfusion and cyclic recruitment/de-recruitment in combination with proinflammatory or biochemical factors is thought to contribute to ALI. One can postulate a 'multiple-hit' theory including surgery-related factors, one-lung ventilation, underlying diseases and co-morbidity, prior therapy and other unidentified events for thoracic surgery patients that may increase susceptibility to ALI [64].

\section{Pulmonary Perfusion and Lung Density Distribution During OLV}

The pulmonary vasculature is the dominant factor in determining perfusion distribution, although gravity influences ventilation to perfusion $(V / Q)$ matching $[65,66]$. Single-photon emission computed tomography (SPECT) data before OLV revealed an almost even distribution of perfusion over both lungs in pigs [25]. Ventilation was primarily distributed to the nondependent lung, similar to preferential ventilation of upper lung regions and perfusion of dependent regions in anesthetized humans in supine position [67]. Perfusion distribution was only slightly affected by gravitation [68]; additionally, even PEEP or the lateral decubitus position had no influence on pulmonary blood flow [69, 70]. After OLV, vasoconstriction in the 

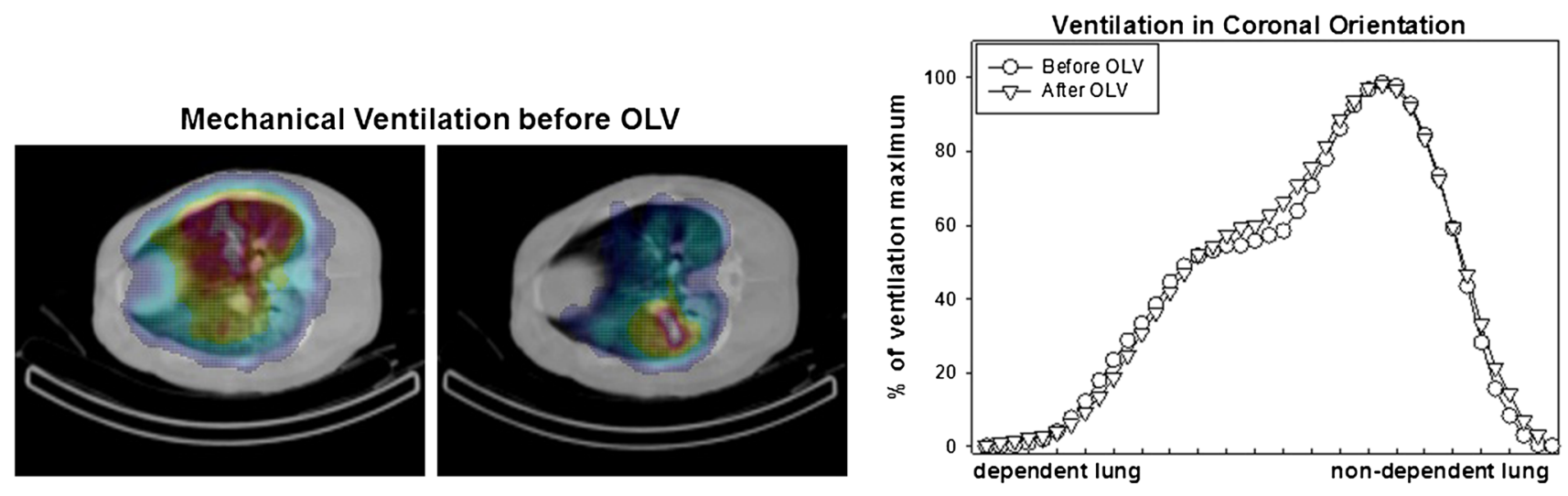

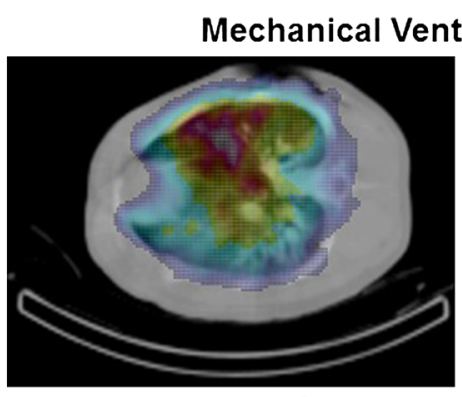

Ventilation ${ }^{81} \mathrm{Kr}$

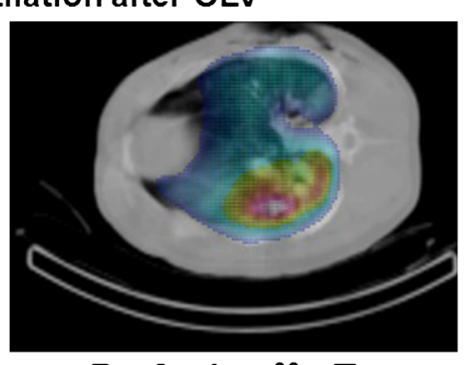

Perfusion ${ }^{99 m}$ Tc

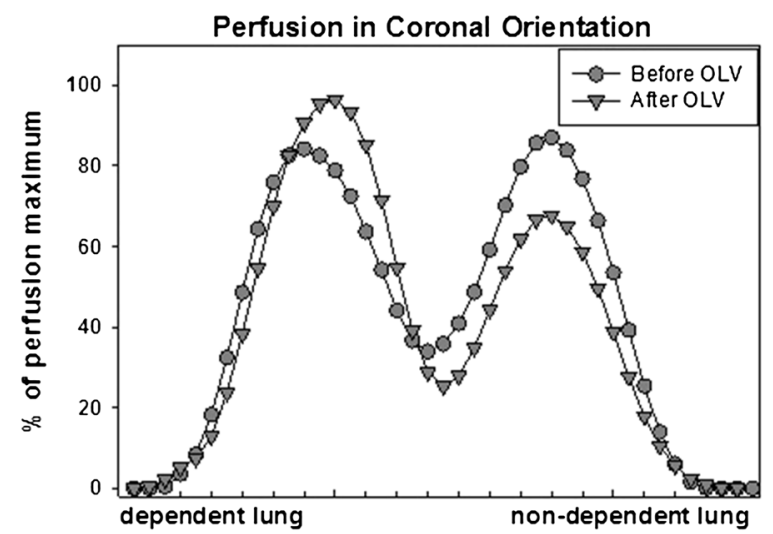

Fig. 1 Effects of one-lung ventilation on distribution of ventilation and perfusion in the lungs. Data from single-photon emission computed tomography. Perfusion is presented by ${ }^{99 m}$ technetium activity and ventilation by ${ }^{81 \mathrm{~m}}$ krypton activity. Whereas ventilation is

upper lung induced by microatelectasis and hypoxic exposure [18] resulted in a continuous decrease of blood flow.

In addition, mechanical stress alters alveolar type II cell mediator release toward a proinflammatory pattern [71]. Since most immune mediators act as vasodilators, cytokine-induced vasodilatation may result in a shift of perfusion to the dependent lung during OLV. This is underlined by the proinflammatory response preferably in the ventilated lung $[62,72]$ in humans and by increased neutrophil infiltration in the dependent lung in pigs [73••].

As obtained from computed tomography lung scans in pigs, OLV reduces consolidated lung compartments and increases the gas content and dependent lung volume $[49,50]$. Atelectatic lung regions are changed into poorly aerated and poorly aerated into normally aerated lung tissue resulting in a shift of the spectrum towards lower density and in significant tidal recruitment within the different density compartments during OLV [74]. In addition, overstretching implies a mechanical force applied to the lung tissue that may occur at the boundaries of atelectatic, poorly and normally aerated tissue [75]. equally distributed before and after OLV, postoperative perfusion is preferentially distributed to the previously ventilated lung and results in significant hyperperfusion. Please note the shift of perfusion maxima to the dependent lung

After collapse, density distribution of the nondependent lungs returned to that before OLV despite complete lung collapse and repetitive vital capacity maneuvers. In contrast, previously ventilated lungs retained an increased lung volume with higher gas content. The fraction of normally aerated lung regions increased according to redistribution of ventilation toward dependent areas. Possible causes include decreased alveolar recoil forces or air trapping (Fig. 1).

OLV-induced lung tissue damage can thus be attributed to hyperperfusion and hyperinflation of the ventilated lung. The increased pulmonary capillary pressures during OLV may cause stress failure of the pulmonary blood-gas barrier with extravasations of fluid into the interstitial space (interstitial edema) and the alveoli (alveolar edema) as well as rupture of small blood vessels (microhemorrhage). This effect is amplified by hyperinflation of the ventilated lung during OLV. Increased airway pressures by relatively high tidal volumes produced overdistension of alveoli and stretching of lung capillaries. In fact, barotrauma of the lung has been associated with ultrastructural changes in the alveolo-capillary membrane, loss of plasma and red blood cells into interstitial and alveolar space [76] (Fig. 2). 
Fig. 2 Histopathological consequences of OLV. Representative lung histology (hematoxylin-eosin staining, $\times 10$ and $\times 40$ ) of the dependent ventilated porcine lung after one-lung ventilation. Please note the characteristic changes: dystelectasis, atelectasis, alveolar overdistension, interstitial edema, microhemorrhage and neutrophil infiltration

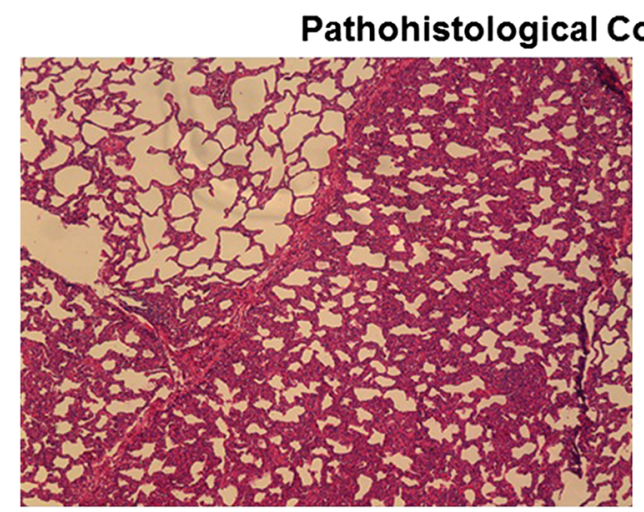

Normally Aerated and Dystelectasis

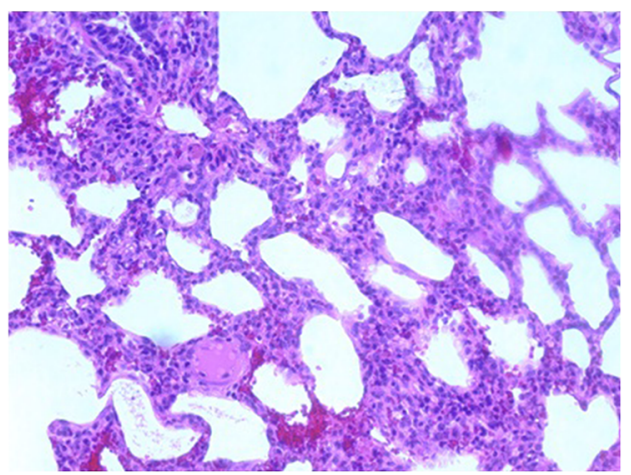

Microhemorrhage/Infiltration

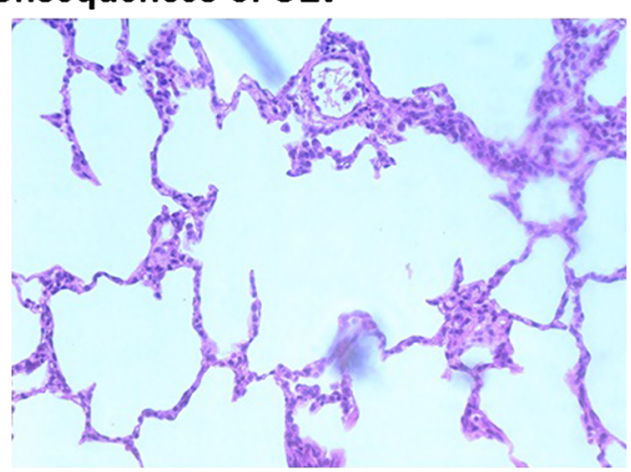

Overaeration and Alveolar Damage

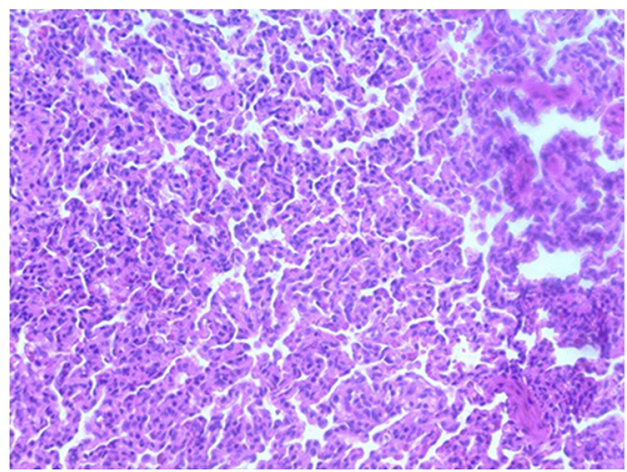

Atelectasis

\section{Cyclic Alveolar Recruitment}

Lung consolidation preferentially in dependent regions is observed rapidly after induction of anesthesia and muscle paralysis in animals and humans [77-79]. Several factors may influence the lung density distribution along the vertical axis. These include regional differences of pleural and transpulmonary pressures with cephalocaudal and vertical gradients, the shape and weight of lung tissue as well as gravity-dependent changes in pulmonary blood volume and compression of the lungs from adjacent anatomical structures [intraabdominal organs [80], exertion and weight of the heart [81].

Influenced by the shape and weight of the lung tissue, the tidal volume is preferentially distributed to nondependent regions [82]. Lateral body position additionally decreases the functional residual capacity in dependent regions and shifts the ventilation maxima to nondependent areas [83].

The volume of atelectasis and poorly aerated lung tissue is already increased before OLV. This can be attributed to bronchoscopic manipulation of the airways open to the atmosphere while inserting and inflating double-lumen tubes and bronchus blockers. However, this procedure is obligatory to obtain sufficient airway separation.

Cyclic recruitment of alveolar units results in shear stress with extensively elevated transmural pressures to the lung parenchyma [84]. Shearing and stretching may have profound consequences on lung function and mediator release, and they have been detected as key factors in initiating an inflammatory response [85-87].

\section{Lung Protection During Thoracic Anesthesia}

The management of patients undergoing thoracic surgery may offer opportunities for anesthetic intervention. Besides the well-recognized advantages of a restrictive fluid management [88.] and sufficient pain therapy in thoracic surgery [89], protective ventilation approaches including pressure-controlled ventilation [90] with low tidal volumes [91, 92, 93•], restriction of inspired oxygen concentrations [94], limitation of inspiratory pressure [6], use of repetitive alveolar recruitment maneuvers [95, 96••] and PEEP [97] as well as inhalation of volatile anesthetics and alternative ventilation approaches are progressively employed. Biologically variable ventilation [98] or even spontaneous breathing [99] may offer new aspects to reduce mechanical stress to lung tissue during OLV [100••].

There is a growing body of evidence that only low tidal volume ventilation of the dependent lung decreases the risk of postpneumonectomy respiratory failure [91, 92]. Consequently, the reduction of tidal volume is an effective 
method to improve outcome, but is not sufficient to completely abolish a proinflammatory response to OLV [52, 62].

Injurious OLV has been demonstrated to increase the recruitment of granulocytes and the expression of proinflammatory mediators in the alveoli of the ventilated lung [62]. The immune response is attenuated by volatile anesthetics (desflurane, sevoflurane) as indicated by decreased alveolar expression of proinflammatory cytokines [72, 101••]. TIVA with propofol results in higher alveolar cytokine concentrations and in increased alveolar granulocyte recruitment. Recent data demonstrate that volatiles also decreased expression of systemic proinflammatory cytokines $[73 \bullet \bullet, 101 \bullet \bullet$ as well as mediators from the non-ventilated lung [102]. The immunodepressant effect in the lung seems to be representative for this class of halogenated drugs. Pharmacological preconditioning by inhalation of volatile anesthetics may thus prevent the organism from mounting a systemic proinflammatory response and can improve the clinical outcome [102]; however, clinical outcome studies are needed [103•].

\section{Alveolar Recruitment Maneuver and PEEP}

Alveolar recruitment maneuvers (ARM) are sufficient to improve arterial oxygenation by the transformation of consolidated lung regions into normally aerated compartments and by the improvement of ventilation and perfusion matching in both lungs during conventional TLV [104] or within the ventilated lung during OLV [95, 96••, 105]. Consolidated dependent and basal regions of the ventilated lung as a result of induction of anesthesia and bronchoscopic airway manipulations could be significantly reduced by application of constant airway pressure of $40 \mathrm{cmH}_{2} \mathrm{O}$ to the whole lung for $10 \mathrm{~s}$ and PEEP of $>5 \mathrm{cmH}_{2} \mathrm{O}$. The restoration of physiological gas/tissue relationships decreases consolidated lung compartments and thereby improves initial conditions for subsequent $\operatorname{OLV}[49,50]$.

However, ARM combined with PEEP may be valuable not only to treat hypoxemia during OLV, but more importantly, as part of a protective ventilation strategy, it may also decrease cyclic alveolar collapse and facilitate reopening of alveolar units. It could be demonstrated that based on the redistribution of gas and tissue after ARM and sufficient PEEP, reduction of tidal volume $\left(V_{\mathrm{T}}=5 \mathrm{ml} / \mathrm{kg}\right)$ during OLV was sufficient to minimize tidal recruitment by preservation of density distributions in the dependent lung and may thus exert protective effects on lung tissue [50]. Moreover, OLV with lower $\mathrm{V}_{\mathrm{T}}$ is not associated with increased atelectasis formation [106].

Mild to moderate PEEP levels are sufficient to keep recruited alveoli open in healthy subjects without deterioration of hemodynamics or hypoxic pulmonary vasoconstriction [107, 108]. An external PEEP of $5 \mathrm{cmH}_{2} \mathrm{O}$ did not increase the total PEEP in patients during OLV [109]. In pigs, PEEP levels of $5-10 \mathrm{cmH}_{2} \mathrm{O}$ are associated with improved oxygenation and continuous lung volume recruitment. Appropriate PEEP however is found only after a recruitment maneuver. A maximum amount of effectively expanded alveoli is yielded by the highest compliance with the lowest dead space fraction [110].

The reduction of $\mathrm{FiO}_{2}$ to 0.4 will protect the lungs from re-collapse for a prolonged period [111]. Furthermore, evidence exists that the lowest possible $\mathrm{F}_{\mathrm{I}} \mathrm{O}_{2}$ should be delivered to the thoracic patient to prevent oxidative damage and postoperative ALI [112]. High oxygen concentrations are associated with a considerable rise in systemic markers of oxidative stress that correlates with postoperative outcome [113].

\section{Conclusions}

One-lung ventilation for thoracic surgery results in significant alveolar damage [26] even in previously healthy lungs [27]. However, this injury may be resolved in normal lungs within hours after mechanical ventilation [31].

One-lung ventilation results in persistent hyperperfusion in the dependent lungs and ventilation/perfusion mismatch. The increased pulmonary blood flow may aggravate stresses to the alveolo-capillary unit and may thus contribute to pulmonary complications after thoracic surgery [25]. During OLV, mechanical stress is additionally increased by enhanced cyclic tidal recruitment of alveoli, indicated by lower compliance and increased airway pressures. This atelectrauma is associated with persistently decreased dependent lung density and increased lung volume after OLV [49]. It is considered to be the main mechanism in the pathogenesis of ventilated lung injury [61]. Alveolar recruitment maneuvers and PEEP reduce consolidated lung compartments during mechanical ventilation. After ARM, OLV with reduced tidal volume does not aggravate cyclic closure and re-opening of alveoli in the ventilated lung. This may have protective effects from mechanical stress on lung tissue and may thus reduce lung injury after OLV. In patients who developed ALI/ARDS after pulmonary resection, the coincidence of OLVinduced lung injury, postoperatively persistent ventilation/ perfusion mismatch and hyperperfusion in the ventilated lung after OLV may have contributed to pathogenesis.

Modern thoracic surgery includes an increasing number of video-assisted thoracoscopic procedures with limited lung manipulation that may lead to lesser-pronounced lung damage [15]. In addition, lung protective ventilation 
strategies are needed to reduce potentially harmful OLVinduced pulmonary injury. It remains to be studied whether protective ventilation modes, the repetitive application of ARM with different PEEP levels, pharmacological preconditioning with inhalational anesthetics or even techniques using spontaneous breathing may result in less severe lung injury and improve outcome.

\section{Compliance with Ethics Guidelines}

Conflict of Interest Alf Kozian and Thomas Schilling declare that they have no conflict of interest.

Human and Animal Rights and Informed Consent This article does not contain any studies with human or animal subjects performed by any of the authors.

\section{References}

Papers of particular interest, published recently, have been highlighted as:

- Of importance

•. Of major importance

1. Alam N, Park BJ, Wilton A, Seshan VE, Bains MS, Downey RJ, et al. Incidence and risk factors for lung injury after lung cancer resection. Ann Thorac Surg. 2007;84(4):1085-91.

2. Boffa DJ, Allen MS, Grab JD, Gaissert HA, Harpole DH, Wright CD. Data from The Society of Thoracic Surgeons General Thoracic Surgery database: the surgical management of primary lung tumors. J Thorac Cardiovasc Surg. 2008;135(2):247-54.

3. Dulu A, Pastores SM, Park B, Riedel E, Rusch V, Halpern NA. Prevalence and mortality of acute lung injury and ARDS after lung resection. Chest. 2006;130(1):73-8.

4. Smetana GW. Postoperative pulmonary complications: an update on risk assessment and reduction. Cleve Clin J Med. 2009;76(Suppl 4):S60-5.

5. Cassivi SD, Allen MS, Vanderwaerdt GD, Ewoldt LL, Cordes ME, Wigle DA, et al. Patient-centered quality indicators for pulmonary resection. Ann Thorac Surg. 2008;86(3):927-32.

6. Licker M, de Perrot M, Spiliopoulos A, Robert J, Diaper J, Chevalley $\mathrm{C}$, et al. Risk factors for acute lung injury after thoracic surgery for lung cancer. Anesth Analg. 2003;97(6): 1558-65.

7. Watanabe S, Asamura H, Suzuki K, Tsuchiya R. Recent results of postoperative mortality for surgical resections in lung cancer. Ann Thorac Surg. 2004;78(3):999-1002.

8. Zeldin RA, Normandin D, Landtwing D, Peters RM. Postpneumonectomy pulmonary edema. J Thorac Cardiovasc Surg. 1984;87(3):359-65.

9. Turnage WS, Lunn JJ. Postpneumonectomy pulmonary edema. A retrospective analysis of associated variables. Chest. 1993;103(6): 1646-50.

10. Bernard GR, Artigas A, Brigham KL, Carlet J, Falke K, Hudson $\mathrm{L}$, et al. The American-European Consensus Conference on ARDS. Definitions, mechanisms, relevant outcomes, and clinical trial coordination. Am J Respir Crit Care Med. 1994;149(3 Pt 1):818-24.
11. Grichnik KP, D’Amico TA. Acute lung injury and acute respiratory distress syndrome after pulmonary resection. Semin Cardiothorac Vasc Anesth. 2004;8(4):317-34.

12. Licker M, Fauconnet P, Villiger Y, Tschopp JM. Acute lung injury and outcomes after thoracic surgery. Curr Opin Anaesthesiol. 2009;22(1):61-7.

13. Deslauriers J, Aucoin A, Gregoire J. Postpneumonectomy pulmonary edema. Chest Surg Clin N Am. 1998;8(3):611-31.

14. Craig SR, Leaver HA, Yap PL, Pugh GC, Walker WS. Acute phase responses following minimal access and conventional thoracic surgery. Eur J Cardiothorac Surg. 2001;20(3):455-63.

15. Whitson BA, D'Cunha J, Andrade RS, Kelly RF, Groth SS, Wu $\mathrm{B}$, et al. Thoracoscopic versus thoracotomy approaches to lobectomy: differential impairment of cellular immunity. Ann Thorac Surg. 2008;86(6):1735-44.

16. Kutlu CA, Williams EA, Evans TW, Pastorino U, Goldstraw P. Acute lung injury and acute respiratory distress syndrome after pulmonary resection. Ann Thorac Surg. 2000;69(2):376-80.

17. Alvarez JM, Bairstow BM, Tang C, Newman MA. Post-lung resection pulmonary edema: a case for aggressive management. J Cardiothorac Vasc Anesth. 1998;12(2):199-205.

18. Liu R, Ueda M, Okazaki N, Ishibe Y. Role of potassium channels in isoflurane- and sevoflurane-induced attenuation of hypoxic pulmonary vasoconstriction in isolated perfused rabbit lungs. Anesthesiology. 2001;95(4):939-46.

19. Wirtz H, Schmidt M. Ventilation and secretion of pulmonary surfactant. Clin Investig. 1992;70(1):3-13.

20. Heerdt PM, Lane P, Pan BY, Schaefer U, Crabtree M, Hong R, et al. Nitrosative stress and myocardial sarcoplasmic endoreticular calcium adenosine triphosphatase subtype 2a activity after lung resection in swine. Anesthesiology. 2007;107(6):954-62.

21. Yin K, Gribbin E, Emanuel S, Orndorff R, Walker J, Weese J, et al. Histochemical alterations in one lung ventilation. J Surg Res. 2007;137(1):16-20.

22. Funakoshi T, Ishibe Y, Okazaki N, Miura K, Liu R, Nagai S, et al. Effect of re-expansion after short-period lung collapse on pulmonary capillary permeability and pro-inflammatory cytokine gene expression in isolated rabbit lungs. Br J Anaesth. 2004;92(4):558-63.

23. Chiumello D, Pristine G, Slutsky AS. Mechanical ventilation affects local and systemic cytokines in an animal model of acute respiratory distress syndrome. Am J Respir Crit Care Med. 1999;160(1):109-16.

24. Tsushima K, King LS, Aggarwal NR, De Gorordo A, D'Alessio FR, Kubo K. Acute lung injury review. Intern Med. 2009;48(9):621-30.

25. Kozian A, Schilling T, Freden F, Maripuu E, Rocken C, Strang $\mathrm{C}$, et al. One-lung ventilation induces hyperperfusion and alveolar damage in the ventilated lung: an experimental study. Br J Anaesth. 2008;100(4):549-59.

26. Kozian A, Schilling T, Rocken C, Breitling C, Hachenberg T, Hedenstierna G. Increased alveolar damage after mechanical ventilation in a porcine model of thoracic surgery. J Cardiothorac Vasc Anesth. 2010;24(4):617-23.

27. Wolthuis EK, Vlaar AP, Choi G, Roelofs JJ, Juffermans NP, Schultz MJ. Mechanical ventilation using non-injurious ventilation settings causes lung injury in the absence of pre-existing lung injury in healthy mice. Crit Care. 2009;13(1):R1.

28. Slutsky AS. Lung injury caused by mechanical ventilation. Chest. 1999;116(90001):9S-a-15.

29. Veldhuizen RA, Tremblay LN, Govindarajan A, van Rozendaal BA, Haagsman HP, Slutsky AS. Pulmonary surfactant is altered during mechanical ventilation of isolated rat lung. Crit Care Med. 2000;28(7):2545-51.

30. Dreyfuss D, Basset G, Soler P, Saumon G. Intermittent positivepressure hyperventilation with high inflation pressures produces 
pulmonary microvascular injury in rats. Am Rev Respir Dis. 1985;132(4):880-4.

31. Vaneker M, Halbertsma FJ, van Egmond J, Netea MG, Dijkman HB, Snijdelaar DG, et al. Mechanical ventilation in healthy mice induces reversible pulmonary and systemic cytokine elevation with preserved alveolar integrity: an in vivo model using clinical relevant ventilation settings. Anesthesiology. 2007;107(3):419-26.

32. Dreyfuss D, Ricard JD, Saumon G. On the physiologic and clinical relevance of lung-borne cytokines during ventilator-induced lung injury. Am J Respir Crit Care Med. 2003;167(11):1467-71.

33. Broccard AF, Hotchkiss JR, Suzuki S, Olson D, Marini JJ. Effects of mean airway pressure and tidal excursion on lung injury induced by mechanical ventilation in an isolated perfused rabbit lung model. Crit Care Med. 1999;27(8):1533-41.

34. Steinberg JM, Schiller HJ, Halter JM, Gatto LA, Lee HM, Pavone LA, et al. Alveolar instability causes early ventilatorinduced lung injury independent of neutrophils. Am J Respir Crit Care Med. 2004;169(1):57-63.

35. Tremblay L, Valenza F, Ribeiro SP, Li J, Slutsky AS. Injurious ventilatory strategies increase cytokines and $c$-fos m-RNA expression in an isolated rat lung model. J Clin Invest. 1997;99(5): 944-52.

36. Dreyfuss D, Saumon G. Ventilator-induced lung injury: lessons from experimental studies. Am J Respir Crit Care Med. 1998;157(1): 294-323.

37. Tremblay LN, Miatto D, Hamid Q, Govindarajan A, Slutsky AS. Injurious ventilation induces widespread pulmonary epithelial expression of tumor necrosis factor-alpha and interleukin-6 messenger RNA. Crit Care Med. 2002;30(8):1693-700.

38. Pugin J. Molecular mechanisms of lung cell activation induced by cyclic stretch. Crit Care Med. 2003;31(4 Suppl):S200-6.

39. Kotani N, Lin CY, Wang JS, Gurley JM, Tolin FP, Michelassi F, et al. Loss of alveolar macrophages during anesthesia and operation in humans. Anesth Analg. 1995;81(6):1255-62.

40. Kotani N, Hashimoto H, Sessler DI, Kikuchi A, Suzuki A, Takahashi $\mathrm{S}$, et al. Intraoperative modulation of alveolar macrophage function during isoflurane and propofol anesthesia. Anesthesiology. 1998;89(5):1125-32.

41. Karzai W, Schwarzkopf K. Hypoxemia during one-lung ventilation: prediction, prevention, and treatment. Anesthesiology. 2009; 110(6): 1402-11.

42. Schwarzkopf K, Klein U, Schreiber T, Preussetaler NP, Bloos F, Helfritsch $\mathrm{H}$, et al. Oxygenation during one-lung ventilation: the effects of inhaled nitric oxide and increasing levels of inspired fraction of oxygen. Anesth Analg. 2001;92(4):842-7.

43. Sticher J, Scholz S, Boning O, Schermuly RT, Schumacher C, Walmrath D, et al. Small-dose nitric oxide improves oxygenation during one-lung ventilation: an experimental study. Anesth Analg. 2002;95(6):1557-62.

44. Ishikawa S, Nakazawa K, Makita K. Progressive changes in arterial oxygenation during one-lung anaesthesia are related to the response to compression of the non-dependent lung. $\mathrm{Br} \mathrm{J}$ Anaesth. 2003;90(1):21-6.

45. Lesser T, Schubert H, Klinzing S. Determination of the sideseparated pulmonary right-to-left shunt volume. J Med Invest. 2008;55(1-2):44-50.

46. Brodsky JB, Fitzmaurice B. Modern anesthetic techniques for thoracic operations. World JSurg. 2001;25(2):162-6.

47. Brodsky JB. The evolution of thoracic anesthesia. Thorac Surg Clin. 2005;15(1):1-10.

48. van der Werff YD, van der Houwen HK, Heijmans PJ, Duurkens VA, Leusink HA, van Heesewijk HP, et al. Postpneumonectomy pulmonary edema. A retrospective analysis of incidence and possible risk factors. Chest. 1997;111(5):1278-84.

49. Kozian A, Schilling T, Schutze H, Heres F, Hachenberg T, Hedenstierna G. Lung computed tomography density distribution in a porcine model of one-lung ventilation. Br J Anaesth. 2009;102(4): 551-60.

50. •• Kozian A, Schilling T, Schutze H, Senturk M, Hachenberg T, Hedenstierna G. Ventilatory protective strategies during thoracic surgery: effects of alveolar recruitment maneuver and low-tidal volume ventilation on lung density distribution. Anesthesiology. 2011;114(5):1025-35. This experimental study examines whether alveolar recruitment maneuvers and low tidal volume ventilation may influence tidal recruitment and lung density distribution. A single recruitment maneuver before OLV has beneficial effects on respiratory mechanics and aeration of the ventilated lung. Subsequent one-lung ventilation with low tidal volumes does not reinforce tidal recruitment, indicating decreased mechanical stress.

51. Farre R, Granell S, Rotger M, Serrano-Mollar A, Closa D, Navajas D. Animal model of unilateral ventilator-induced lung injury. Intensive Care Med. 2005;31(3):487-90.

52. Wrigge $\mathrm{H}$, Uhlig U, Zinserling J, Behrends-Callsen E, Ottersbach G, Fischer M, et al. The effects of different ventilatory settings on pulmonary and systemic inflammatory responses during major surgery. Anesth Analg. 2004;98(3):775-81.

53. Padley SP, Jordan SJ, Goldstraw P, Wells AU, Hansell DM. Asymmetric ARDS following pulmonary resection: CT findings initial observations. Radiology. 2002;223(2):468-73.

54. Amato MB, Barbas CS, Medeiros DM, Magaldi RB, Schettino GP, Lorenzi-Filho G, et al. Effect of a protective-ventilation strategy on mortality in the acute respiratory distress syndrome. N Engl J Med. 1998;338(6):347-54.

55. The Acute Respiratory Distress Syndrome Network. Ventilation with lower tidal volumes as compared with traditional tidal volumes for acute lung injury and the acute respiratory distress syndrome. The Acute Respiratory Distress Syndrome Network. N Engl J Med. 2000;342(18):1301-8.

56. Tugrul M, Camci E, Karadeniz H, Senturk M, Pembeci K, Akpir K. Comparison of volume controlled with pressure controlled ventilation during one-lung anaesthesia. Br J Anaesth. 1997;79(3): 306-10.

57. de Abreu MG, Heintz M, Heller A, Szechenyi R, Albrecht DM, Koch T. One-lung ventilation with high tidal volumes and zero positive end-expiratory pressure is injurious in the isolated rabbit lung model. Anesth Analg. 2003;96(1):220-8.

58. Jeon K, Yoon JW, Suh GY, Kim J, Kim K, Yang M, et al. Risk factors for post-pneumonectomy acute lung injury/acute respiratory distress syndrome in primary lung cancer patients. Anaesth Intensive Care. 2009;37(1):14-9.

59. Licker M, Diaper J, Villiger Y, Spiliopoulos A, Licker V, Robert $\mathrm{J}$, et al. Impact of intraoperative lung-protective interventions in patients undergoing lung cancer surgery. Crit Care. 2009;13(2): R41.

60. Dreyfuss D, Saumon G. Role of tidal volume, FRC, and endinspiratory volume in the development of pulmonary edema following mechanical ventilation. Am Rev Respir Dis. 1993;148(5): 1194-203.

61. Chu EK, Whitehead T, Slutsky AS. Effects of cyclic opening and closing at low- and high-volume ventilation on bronchoalveolar lavage cytokines. Crit Care Med. 2004;32(1):168-74.

62. Schilling T, Kozian A, Huth C, Buhling F, Kretzschmar M, Welte $\mathrm{T}$, et al. The pulmonary immune effects of mechanical ventilation in patients undergoing thoracic surgery. Anesth Analg. 2005;101(4):957-65.

63. D’Angelo E, Pecchiari M, Della Valle P, Koutsoukou A, MilicEmili J. Effects of mechanical ventilation at low lung volume on respiratory mechanics and nitric oxide exhalation in normal rabbits. J Appl Physiol. 2005;99(2):433-44.

64. Lytle FT, Brown DR. Appropriate ventilatory settings for thoracic surgery: intraoperative and postoperative. Semin Cardiothorac Vasc Anesth. 2008;12(2):97-108. 
65. Milic-Emili J, Henderson JA, Dolovich MB, Trop D, Kaneko K. Regional distribution of inspired gas in the lung. J Appl Physiol. 1966;21(3):749-59.

66. West JB, Dollery CT, Naimark A. Distribution of blood flow in isolated lung; relation to vascular and alveolar pressures. J Appl Physiol. 1964;19:713-24.

67. Tokics L, Hedenstierna G, Svensson L, Brismar B, Cederlund T, Lundquist $\mathrm{H}$, et al. V/Q distribution and correlation to atelectasis in anesthetized paralyzed humans. J Appl Physiol. 1996;81(4): 1822-33.

68. Galvin I, Drummond GB, Nirmalan M. Distribution of blood flow and ventilation in the lung: gravity is not the only factor. $\mathrm{Br}$ J Anaesth. 2007;98(4):420-8.

69. Kallas HJ, Domino KB, Glenny RW, Anderson EA, Hlastala MP. Pulmonary blood flow redistribution with low levels of positive end-expiratory pressure. Anesthesiology. 1998;88(5):1291-9.

70. Walther SM, Domino KB, Glenny RW, Hlastala MP. Positive end-expiratory pressure redistributes perfusion to dependent lung regions in supine but not in prone lambs. Crit Care Med. 1999;27(1):37-45.

71. Hammerschmidt S, Kuhn H, Sack U, Schlenska A, Gessner C, Gillissen A, et al. Mechanical stretch alters alveolar type II cell mediator release toward a proinflammatory pattern. Am J Respir Cell Mol Biol. 2005;33(2):203-10.

72. Schilling T, Kozian A, Kretzschmar M, Huth C, Welte T, Buhling F, et al. Effects of propofol and desflurane anaesthesia on the alveolar inflammatory response to one-lung ventilation. Br J Anaesth. 2007;99(3):368-75.

73. • Schilling T, Kretzschmar M, Hachenberg T, Hedenstier-Na G, Kozian A. The immune response to one-lung-ventilation is not affected by repeated alveolar recruitment manoeuvres in pigs. Minerva Anestesiol. 2013;79(6):590-603. This study demonstrates the alveolar proinflammatory response induced by $O L V$ for thoracic surgery results. Alveolar recruitment maneuvers and standard ventilation do not extend inflammation in healthy porcine lungs. Desflurane anesthesia attenuates both pulmonary and systemic cytokine release, but less than propofol, and does not modulate $\mathrm{mRNA}$ expression.

74. Malbouisson LM, Muller JC, Constantin JM, Lu Q, Puybasset L, Rouby JJ. Computed tomography assessment of positive endexpiratory pressure-induced alveolar recruitment in patients with acute respiratory distress syndrome. Am J Respir Crit Care Med. 2001;163(6):1444-50.

75. Marini JJ. Recruitment maneuvers to achieve an "open lung"whether and how? Crit Care Med. 2001;29(8):1647-8.

76. Lopez-Aguilar J, Piacentini E, Villagra A, Murias G, Pascotto S, Saenz-Valiente A, et al. Contributions of vascular flow and pulmonary capillary pressure to ventilator-induced lung injury. Crit Care Med. 2006;34(4):1106-12.

77. David M, Karmrodt J, Bletz C, David S, Herweling A, Kauczor $\mathrm{HU}$, et al. Analysis of atelectasis, ventilated, and hyperinflated lung during mechanical ventilation by dynamic CT. Chest. 2005;128(5):3757-70.

78. Reber A, Engberg G, Sporre B, Kviele L, Rothen HU, Wegenius $\mathrm{G}$, et al. Volumetric analysis of aeration in the lungs during general anaesthesia. Br J Anaesth. 1996;76(6):760-6.

79. Rothen HU, Sporre B, Engberg G, Wegenius G, Hedenstierna G. Airway closure, atelectasis and gas exchange during general anaesthesia. Br J Anaesth. 1998;81(5):681-6.

80. Roussos CS, Martin RR, Engel LA. Diaphragmatic contraction and the gradient of alveolar expansion in the lateral posture. J Appl Physiol. 1977;43(1):32-8.

81. Malbouisson LM, Busch CJ, Puybasset L, Lu Q, Cluzel P, Rouby JJ. Role of the heart in the loss of aeration characterizing lower lobes in acute respiratory distress syndrome. CT Scan
ARDS Study Group. Am J Respir Crit Care Med. 2000;161(6): 2005-12.

82. Rehder K, Sessler AD, Rodarte JR. Regional intrapulmonary gas distribution in awake and anesthetized-paralyzed man. J Appl Physiol. 1977;42(3):391-402.

83. Klingstedt $\mathrm{C}$, Hedenstierna $\mathrm{G}$, Baehrendtz S, Lundqvist $\mathrm{H}$, Strandberg A, Tokics L, et al. Ventilation-perfusion relationships and atelectasis formation in the supine and lateral positions during conventional mechanical and differential ventilation. Acta Anaesthesiol Scand. 1990;34(6):421-9.

84. Mead J, Takishima T, Leith D. Stress distribution in lungs: a model of pulmonary elasticity. J Appl Physiol. 1970;28(5):596-608.

85. International consensus conferences in intensive care medicine. Ventilator-associated Lung Injury in ARDS. This official conference report was cosponsored by the American Thoracic Society, The European Society of Intensive Care Medicine, and The Societe de Reanimation de Langue Francaise, and was approved by the ATS Board of Directors, July 1999. Am J Respir Crit Care Med. 1999;160(6):2118-24.

86. Oudin S, Pugin J. Role of MAP kinase activation in interleukin8 production by human BEAS-2B bronchial epithelial cells submitted to cyclic stretch. Am J Respir Cell Mol Biol. 2002; 27(1):107-14

87. Thomas RA, Norman JC, Huynh TT, Williams B, Bolton SJ, Wardlaw AJ. Mechanical stretch has contrasting effects on mediator release from bronchial epithelial cells, with a rhokinase-dependent component to the mechanotransduction pathway. Respir Med. 2006;100(9):1588-97.

88. - Assaad S, Popescu W, Perrino A. Fluid management in thoracic surgery. Curr Opin Anaesthesiol. 2013;26(1):31-9. This comprehensive review presents the current available data regarding the perioperative risks associated with fluid management in thoracic surgery and its implications on the development of acute lung injury as well as acute kidney injury. Alternative fluid regimens to the traditional restrictive protocols used during thoracic surgery are being explored. These include normovolemic and goal-directed therapy protocols and the use of newer colloid solutions.

89. Licker M, Spiliopoulos A, Tschopp JM. Influence of thoracic epidural analgesia on cardiovascular autonomic control after thoracic surgery. Br J Anaesth. 2003;91(4):525-31.

90. Unzueta MC, Casas JI, Moral MV. Pressure-controlled versus volume-controlled ventilation during one-lung ventilation for thoracic surgery. Anesth Analg. 2007;104(5):1029-33.

91. Fernandez-Perez ER, Keegan MT, Brown DR, Hubmayr RD, Gajic $O$. Intraoperative tidal volume as a risk factor for respiratory failure after pneumonectomy. Anesthesiology. 2006;105(1):14-8.

92. Michelet P, D'Journo XB, Roch A, Doddoli C, Marin V, Papazian $\mathrm{L}$, et al. Protective ventilation influences systemic inflammation after esophagectomy: a randomized controlled study. Anesthesiology. 2006;105(5):911-9.

93. • Yang M, Ahn HJ, Kim K, Kim JA, Yi CA, Kim MJ, et al. Does a protective ventilation strategy reduce the risk of pulmonary complications after lung cancer surgery? A randomized controlled trial. Chest. 2011;139(3):530-7. This clinical study was undertaken to examine whether protective ventilatory settings would attenuate lung impairment during one-lung ventilation compared with conventional ventilation in patients undergoing lung resection surgery. It was established that in comparison with the traditional ventilation approaches, application of small tidal volumes and PEEP through pressure-controlled ventilation was associated with a lower incidence of postoperative lung dysfunction.

94. Cheng YJ, Chan KC, Chien CT, Sun WZ, Lin CJ. Oxidative stress during 1-lung ventilation. J Thorac Cardiovasc Surg. 2006;132(3):513-8. 
95. Tusman G, Bohm SH, Sipmann FS, Maisch S. Lung recruitment improves the efficiency of ventilation and gas exchange during onelung ventilation anesthesia. Anesth Analg. 2004;98(6):1604-9.

96. • Unzueta C, Tusman G, Suarez-Sipmann F, Bohm S, Moral V. Alveolar recruitment improves ventilation during thoracic surgery: A randomized controlled trial. Br J Anaesth. 2012;108(3): 517-24. This trial was conducted to determine whether an alveolar recruitment strategy applied just before starting onelung ventilation improves ventilatory efficiency. It was found that recruitment of both lungs before instituting OLV not only decreased alveolar dead space, but also improved arterial oxygenation and the efficiency of ventilation.

97. Ren Y, Peng ZL, Xue QS, Yu BW. The effect of timing of application of positive end-expiratory pressure on oxygenation during one-lung ventilation. Anaesth Int Care. 2008;36(4):544-8.

98. McMullen MC, Girling LG, Graham MR, Mutch WA. Biologically variable ventilation improves oxygenation and respiratory mechanics during one-lung ventilation. Anesthesiology. 2006; 105(1):91-7.

99. Pompeo E, Mineo TC. Awake operative videothoracoscopic pulmonary resections. Thorac Surg Clin. 2008;18(3):311-20.

100. • Karcz M, Vitkus A, Papadakos PJ, Schwaiberger D, Lachmann B. State-of-the-art mechanical ventilation. J Cardiothorac Vasc Anesth. 2012;26(3):486-506. This comprehensive review highlights the benefits of physiologic-based mechanical ventilation with the aim of ensuring that patients receive the optimal mode of mechanical ventilation, which minimizes the risk of ventilator-induced lung injury.

101. • Schilling T, Kozian A, Senturk M, Huth C, Reinhold A, Hedenstierna G, et al. Effects of volatile and intravenous anesthesia on the alveolar and systemic inflammatory response in thoracic surgical patients. Anesthesiology. 2011;115(1):65-74. This clinical study demonstrates that OLV induces release of proinflammatory substances into the alveoli of the ventilated lung in patients undergoing open thoracic surgery. The administration of halogenated volatile anesthetics, such as desflurane or sevoflurane, suppresses pulmonary cytokine release, but not the immediate systemic inflammatory response to $O L V$ and thoracic surgery.

102. De Conno E, Steurer MP, Wittlinger M, Zalunardo MP, Weder W, Schneiter D, et al. Anesthetic-induced improvement of the inflammatory response to one-lung ventilation. Anesthesiology. 2009;110(6):1316-26.
103. Modolo NS, Modolo MP, Marton MA, Volpato E, Monteiro Arantes V, do Nascimento Junior P, et al. Intravenous versus inhalation anaesthesia for one-lung ventilation. Cochrane Database Syst Rev. 2013;7:CD006313. The objective of this metaanalysis in more than 800 patients was to evaluate the effectiveness and safety of anesthetic drugs in thoracic surgery. However, only small evidence from randomized controlled trials suggests differences in participant outcomes with anaesthesia maintained by intravenous versus inhalational anaesthesia during one-lung ventilation.

104. Tusman G, Bohm SH, Suarez-Sipmann F, Turchetto E. Alveolar recruitment improves ventilatory efficiency of the lungs during anesthesia. Can J Anaesth. 2004;51(7):723-7.

105. Tusman G, Bohm SH, Melkun F, Staltari D, Quinzio C, Nador C, et al. Alveolar recruitment strategy increases arterial oxygenation during one-lung ventilation. Ann Thorac Surg. 2002;73(4):1204-9.

106. Cai H, Gong H, Zhang L, Wang Y, Tian Y. Effect of low tidal volume ventilation on atelectasis in patients during general anesthesia: a computed tomographic scan. J Clin Anesth. 2007;19(2):125-9.

107. Inomata S, Nishikawa T, Saito S, Kihara S. "Best" PEEP during one-lung ventilation. Br J Anaesth. 1997;78(6):754-6.

108. Villar J, Herrera-Abreu MT, Valladares F, Muros M, PerezMendez L, Flores C, et al. Experimental ventilator-induced lung injury: exacerbation by positive end-expiratory pressure. Anesthesiology. 2009;110(6):1341-7.

109. Slinger PD, Hickey DR. The interaction between applied peep and auto-peep during one-lung ventilation. J Cardiothorac Vasc Anesth. 1998;12(2):133-6.

110. Maisch S, Reissmann H, Fuellekrug B, Weismann D, Rutkowski T, Tusman G, et al. Compliance and dead space fraction indicate an optimal level of positive end-expiratory pressure after recruitment in anesthetized patients. Anesth Analg. 2008;106(1):175-81.

111. Rothen HU, Sporre B, Engberg G, Wegenius G, Hogman M, Hedenstierna G. Influence of gas composition on recurrence of atelectasis after a reexpansion maneuver during general anesthesia. Anesthesiology. 1995;82(4):832-42.

112. Williams EA, Quinlan GJ, Goldstraw P, Gothard JW, Evans TW. Postoperative lung injury and oxidative damage in patients undergoing pulmonary resection. Eur Respir J. 1998;11(5):1028-34.

113. Misthos P, Katsaragakis S, Theodorou D, Milingos N, Skottis I. The degree of oxidative stress is associated with major adverse effects after lung resection: a prospective study. Eur J Cardiothorac Surg. 2006;29(4):591-5. 